\title{
Role of Transcranial Direct Current Stimulation in the Management of Alzheimer's Disease: A Meta-analysis of Effects, Adherence and Adverse Effects
}

\author{
Vrinda Saxena', Arghya Pal ${ }^{2}$ \\ ${ }^{1}$ Department of Psychiatry, Himalayan Institute of Medical Sciences, Swami Rama Himalayan University, Dehradun, ${ }^{2}$ Department of Psychiatry, \\ All India Institute of Medical Sciences, Raebareli, India
}

Transcranial direct current stimulation (tDCS) is a form of novel brain stimulating method that has attracted interest owing to its relative inexpensiveness and ease of administration. It has been evaluated in many studies for its effectiveness in improving cognitive symptoms in Alzheimer's disease (AD). However, our understanding regarding its efficacy and the most effective way of administering tDCS (in terms of lead placement to achieve response and prevent harmful consequences) is still evolving. The current meta-analysis was conducted to resolve the above issues. A search using appropriate keywords and medical subject headings was conducted on PubMed, Scopus and DOAJ database. Studies were analysed on pre-defined inclusion and exclusion criteria. Finally 11 studies were included for quantitative analysis from 1,021 obtained from initial search. All the studies included were methodologically of high quality, though an asymmetrical funnel plot raised the possibility of publication bias. tDCS was found to significantly improve the scores on cognition as compared to sham. Anodal tDCS was found to be significantly beneficial in this regards, whereas cathodal and dual stimulation were not. There were no significant difference in the number of drop-outs and adverse reaction in tDCS and sham group. The quality of evidence that we have reviewed in this study is robust. tDCS, particularly anodal tDCS is an effective treatment modality in AD. It is well tolerated in patients with AD. However, further studies are warranted to probe the role of tDCS in other domains of AD.

KEY WORDS: Transcranial direct current stimulation; Alzheimer's disease; Major neurocognitive disorder; Brain stimulation; Meta-analysis.

\section{INTRODUCTION}

Dementia is a syndrome where there is decline in cognitive functions beyond what it is expected in normal aging, which ultimately hampers the day to day activity. Diagnostic and Statistical Manual of Mental Disorders (DSM 5) [1] replaced the term 'dementia' with Major and minor neurocognitive disorders. Alzheimer disease (AD) is the most common cause of dementia for patients older than 65 years of age, consisting of more than $60 \%$ of all cases of dementia worldwide. Alzheimer disease can be

Received: February 16, 2021 / Revised: March 5, 2021

Accepted: March 6, 2021

Address for correspondence: Arghya Pal

Department of Psychiatry, All India Institute of Medical Sciences, Raebareli, Uttar Pradesh 229405, India

E-mail: drarghyamb@gmail.com

ORCID: https://orcid.org/0000-0002-5887-1971 divided into two groups; sporadic and familial. Sporadic form is more common and typically late onset while familial form has early onset. Memory impairment is the most common initial symptom of Alzheimer disease but symptoms can range from impaired executive function, problem solving to behavioural, psychiatric and motor symptoms. Direct and indirect cost related to Alzheimer's disease alone was more than 500 billion USD annually [2]. AD is diagnosed clinically after excluding other causes of dementia. But it can be diagnosed definitively in a living patient with analysis of Cerebrospinal fluid and Positron emission therapy (PET) scan biomarkers combined with some clinical criteria [3].

Currently, there is no cure for $\mathrm{AD}$, but we can slow the disease progression by medications, lifestyle and dietary modifications. Acetylcholinesterase-inhibitors like donepezil, rivastigmine, galantamine with or without $\mathrm{N}$ methyl

(c) This is an Open-Access article distributed under the terms of the Creative Commons Attribution Non-Commercial License (http://creativecommons.org/licenses/by-nc/4.0) which permits unrestricted non-commercial use, distribution, and reproduction in any medium, provided the original work is properly cited. 
$\mathrm{D}$ aspartic acid (NMDA) receptor antagonist memantine are most widely used [4]. Brain stimulation techniques are a relatively new breakthrough in halting the progression of AD. Generally, three types of brain stimulation techniques are in use currently; Repetitive transcranial magnetic stimulation, transcranial direct current stimulation (tDCS) and deep brain stimulation (DBS). Among them we think tDCS is particularly important in AD management because the device is portable, cheap and treatment is very convenient which doesn't hamper day-to day activities. tDCS uses very low intensity current, so it can be done as an out-patient procedure without anaesthesia. It is particularly important for developing countries with low healthcare budgets and where more percentage of patients depend on daily wages. Patients should be more compliant with the treatment because it can be done in a relatively shorter time span.

Cruz Gonzalez et al. [5] in their meta-analysis of 12 studies including 195 patients of dementia and 53 patients with mild cognitive impairment, found that tDCS can lead to improvement in various domains like memory and language; at least on a short term basis. Cai et al. [6] in their meta-analysis of 146 patients of AD also found benefit in improvement of cognitive functioning of mild and moderate AD. Their study also showed that as compared to repeated tDCS, single sessions of tDCS was significantly effective. In this context, the meta-analysis of 8 studies by Inagawa et al. [7] did not find anodal tDCS to have enough evidence to suggest efficacy, probably due to small number of studies and sample size. Thus, to summarize, though tDCS is deemed to have benefit in the management of $A D$, there are multiple questions that remain unanswered, especially regarding lead placement, treatment adherence and chances of adverse effects. The current meta-analysis was conducted to summarize the evidence of $\mathrm{tDCS}$ in management of $\mathrm{AD}$, with focus on trying to answer the unresolved issues.

\section{METHODOLOGY}

\section{Scope}

The current review was conducted to study to address the following research question:

- Can tDCS be used to improve cognitive outcomes in patients with $\mathrm{AD}$ ?

- Is there any difference in the type of tDCS stimulation improving cognitive outcomes in patients with $\mathrm{AD}$ ?

- Is tDCS well tolerated in patients with AD?

\section{Search Strategy}

Two researchers individually conducted search using the same search terms in the same search engines. PubMed, Scopus and DOAJ database were searched until July, 2020. The search terms included were "tDCS"/ "Transcranial direct current stimulation" AND "Alzheimer"/ "Alzheimer's disease"/“Alzheimer Disease”/“Neurocognitive disorder"/“mild cognitive impairment”/“Dementia”. Full text of each articles was reviewed and they were separately screened by both the researchers. Any disagreements regarding inclusion and exclusion of articles were resolved with the help of a third expert (who is not a author of this manuscript).

\section{Study Selection}

Our study selection included randomized control trials with parallel and cross over design to ensure wide ranging coverage of studies.

\section{Inclusion criteria}

Inclusion criteria comprised of: (a) Studies that included subjects diagnosed with AD based on a standard diagnostic criteria. (b) Cognitive impairment measured by a scale with quantifiable assessment. (c) tDCS was used as an intervention that results in outcome differences between active and control group. (d) Outcomes are measured by scales that measured various aspects of cognition and gave quantifiable assessment. (e) Studies included randomized control trials and original articles. (f) Full text of article could be accessed and was in English. (g) Studies provided original data that included mean and standard deviation (SD) or provided other variables that could be converted into mean and SD.

\section{Exclusion criteria}

Studies with the following contents were excluded. (a) Experimental studies using animals. (b) Reviews and case reports, conference abstracts and newspaper articles were excluded. (c) repeatedly published studies. (d) Studies involving subjects with other types of dementias or other cause of neurocognitive decline and involving other modalities of brain stimulation apart from tDCS. 
Table 1. Table showing characteristics of studies included in meta analysis

\begin{tabular}{|c|c|c|c|c|c|c|c|c|c|}
\hline Study & $\begin{array}{l}\text { Sample } \\
\text { size }\end{array}$ & Design & Age (yr) & $\begin{array}{l}\text { Sex } \\
(M / F)\end{array}$ & $\begin{array}{l}\text { Education } \\
\qquad(y r)\end{array}$ & $\begin{array}{l}\text { Duration of } \\
\text { disease (yr) }\end{array}$ & $\begin{array}{c}\text { Level of } \\
\text { cognition } \\
\text { (MMSE scores) }\end{array}$ & Outcome & $\begin{array}{l}\text { Parameters of } \\
\text { stimulation }\end{array}$ \\
\hline $\begin{array}{r}\text { Boggio et al. } \\
(2012)[10]\end{array}$ & $\begin{array}{l}\text { NE: } 15 \\
\text { NC: } 15\end{array}$ & Crossover & $\begin{array}{l}77.5 \pm 6.9 \\
80.6 \pm 9.5\end{array}$ & $\begin{array}{l}4 / 4 \\
4 / 3\end{array}$ & $\begin{array}{l}13.3 \pm 4.8 \\
15.7 \pm 0.8\end{array}$ & $\begin{array}{l}5.0 \pm 1.1 \\
3.7 \pm 2.4\end{array}$ & $\begin{array}{l}\text { Mild to } \\
\text { moderate } \\
(\geq 15)\end{array}$ & $\begin{array}{l}\text { VRT } \\
\text { MMSE }\end{array}$ & $\begin{array}{l}\text { Anodal; } 0.06 \mathrm{~mA} / \mathrm{cm}^{2} \\
30 \mathrm{~min} / \mathrm{d}, 5 \mathrm{~d} \text {; } \\
\text { temporal lobes } \\
\text { bilaterally }\end{array}$ \\
\hline $\begin{array}{l}\text { Gangemi et al. } \\
\text { (2021) [13] }\end{array}$ & & & & & & & & & $\begin{array}{l}\text { Anodal: left FT lobe, } \\
\text { Reference: right frontal }\end{array}$ \\
\hline Study 1 & $\begin{array}{l}\text { NE: } 13 \\
\text { NC: } 13\end{array}$ & Parallel & $\begin{array}{r}67.5 \pm 2.8 \\
69.01 \pm 3.1\end{array}$ & NR & $\begin{array}{l}6.5 \pm 2 \\
6.1 \pm 2.1\end{array}$ & NR & $\begin{array}{r}15.15 \pm 2.49 \\
16 \pm 1.71\end{array}$ & $\begin{array}{l}\text { MMSE } \\
\text { MODA }\end{array}$ & $\begin{array}{l}\text { lobe. } \\
2.5 \mathrm{~mA} / \mathrm{cm}^{2} / \mathrm{d} \text { for } 10 \mathrm{~d}\end{array}$ \\
\hline Study 2 & $\begin{array}{l}\text { NE: } 9 \\
\text { NC: } 9\end{array}$ & & $\begin{array}{l}68.5 \pm 2.8 \\
68.7 \pm 3.1\end{array}$ & & $\begin{array}{l}6.7 \pm 2 \\
6.2 \pm 2.7\end{array}$ & & $\begin{array}{l}15.8 \pm 1.8 \\
15.9 \pm 1.6\end{array}$ & $\begin{array}{l}\text { MMSE } \\
\text { MODA }\end{array}$ & $\begin{array}{l}\text { Anodal: left FT lobe, } \\
\text { Reference: right frontal } \\
\text { lobe. } \\
2.5 \mathrm{~mA} / \mathrm{cm}^{2} / \mathrm{d} \text { for } \\
10 \mathrm{~d} \text { each month for } \\
8 \text { months }\end{array}$ \\
\hline $\begin{array}{c}\text { Ferrucci et al. } \\
\text { (2008) [12] }\end{array}$ & $\begin{array}{l}\text { NE: } 10 \\
\text { NC: } 10\end{array}$ & Crossover & $75.2 \pm 7.3$ & $3 / 7$ & $10.9 \pm 4.8$ & NR & Mild $(\geq 20)$ & $\begin{array}{l}\text { WRT } \\
\text { MMSE }\end{array}$ & $\begin{array}{l}\text { Anodal and cathodal; } \\
0.06 \mathrm{~mA} / \mathrm{cm}^{2} \\
1 \text { session of } 15 \mathrm{~min} ; \\
3 \text { months; } \\
\text { temporo-parietal } \\
\text { areas bilaterally }\end{array}$ \\
\hline $\begin{array}{l}\text { Lu et al. } \\
\qquad \text { (2019) [18] }\end{array}$ & $\begin{array}{l}\text { NE: } 69 \\
\text { NC: } 64\end{array}$ & RCT & $\begin{array}{l}74.2 \pm 6.7 \\
74.5 \pm 6.6\end{array}$ & $\begin{array}{l}42 / 21 \\
36 / 17\end{array}$ & $\begin{array}{l}7.3 \pm 4.8 \\
6.5 \pm 4.3\end{array}$ & $N R$ & $\begin{array}{l}25.7 \pm 2.6 \\
25.6 \pm 2.9\end{array}$ & $\begin{array}{l}\text { MMSE } \\
\text { CVFT } \\
\text { TMT }\end{array}$ & $\begin{array}{l}\text { Anodal; } 2 \mathrm{~mA} / \mathrm{cm}^{2} \\
20 \mathrm{~min} / \mathrm{d} \text {, } \\
3 \mathrm{session} / \mathrm{wk}, \\
3 \mathrm{month} \text {; left lateral } \\
\text { temporal cortex }\end{array}$ \\
\hline $\begin{array}{c}\text { Bystad et al. } \\
\text { (2016) [9] }\end{array}$ & $\begin{array}{l}\text { NE: } 12 \\
\text { NC: } 13\end{array}$ & Parallel & $\begin{array}{l}70.0 \pm 8.0 \\
75.0 \pm 8.7\end{array}$ & $\begin{array}{l}7 / 5 \\
7 / 6\end{array}$ & NR & NR & $\begin{array}{l}\text { Mild to } \\
\text { moderate } \\
(\geq 18)\end{array}$ & $\begin{array}{l}\text { CVLT-II } \\
\text { Recognition } \\
\text { MMSE }\end{array}$ & $\begin{array}{l}\text { Anodal; } 0.06 \mathrm{~mA} / \mathrm{cm}^{2} \\
30 \mathrm{~min} / \mathrm{d}, 6 \mathrm{~d} ; \\
\text { left temporal lobe }\end{array}$ \\
\hline $\begin{array}{l}\text { Inagawa et al. } \\
\text { (2019) [15] }\end{array}$ & $\begin{array}{l}\text { NE: } 7 \\
\text { NC: } 13\end{array}$ & $\begin{array}{l}\text { Parallel, } \\
\text { RCT }\end{array}$ & $\begin{array}{l}76.6 \pm 5.7 \\
76.2 \pm 7.7\end{array}$ & $\begin{array}{l}3 / 4 \\
7 / 6\end{array}$ & NR & $\begin{array}{l}0.9 \pm 1.2 \\
1.2 \pm 1.5\end{array}$ & $\begin{array}{l}\text { Moderate } \\
\text { MMSE }<18\end{array}$ & $\begin{array}{l}\text { MMSE } \\
\text { FAB } \\
\text { CDR } \\
\text { ADAS Cog }\end{array}$ & $\begin{array}{l}\text { Anodal: DLPFC } \\
\text { Cathodal: C/L } \\
\text { supraorbital ridge } \\
2 \mathrm{~mA} / \mathrm{d} \text {, } \\
20 \mathrm{~min} / \mathrm{session}, \\
2 \text { session/day for } \\
5 \text { days }\end{array}$ \\
\hline $\begin{array}{l}\text { Im et al. } \\
\quad(2019)[14]\end{array}$ & $\begin{array}{l}\text { NE: } 12 \\
\text { NC: } 8\end{array}$ & RCT & $\begin{array}{l}71.9 \pm 9.2 \\
74.9 \pm 5\end{array}$ & $\begin{array}{l}1 / 10 \\
2 / 5\end{array}$ & $\begin{array}{l}6.3 \pm 3.8 \\
5.4 \pm 5.9\end{array}$ & NR & $\begin{array}{l}20.1 \pm 3.8 \\
22.1 \pm 4.6\end{array}$ & $\begin{array}{l}\text { MMSE } \\
\text { CDR } \\
\text { CDR-SOB }\end{array}$ & $\begin{array}{l}\text { Anodal: left DLPFC } \\
\text { Cathodal: right DLPFC } \\
2 \mathrm{~mA} \text { for } 30 \mathrm{~min} / \text { day } \\
\text { for } 6 \text { months }\end{array}$ \\
\hline $\begin{array}{l}\text { Cotelli et al. } \\
\text { (2014) [11] }\end{array}$ & $\begin{array}{l}\text { NE: } 12 \\
\text { NC: } 12\end{array}$ & Parallel & $\begin{array}{l}76.6 \pm 4.6 \\
74.7 \pm 6.1\end{array}$ & $\begin{array}{l}2 / 10 \\
3 / 9\end{array}$ & $\begin{array}{l}5.5 \pm 2.4 \\
8.9 \pm 5.1\end{array}$ & NR & $\begin{array}{l}\text { Mild to } \\
\text { moderate } \\
\text { (above 20) }\end{array}$ & $\begin{array}{l}\text { FNAT } \\
\text { MMSE }\end{array}$ & $\begin{array}{l}\text { Anodal; } 0.08 \mathrm{~mA} / \mathrm{cm}^{2} \\
25 \mathrm{~min} / \mathrm{d}, 10 \mathrm{~d} \\
\text { left DLPFC }\end{array}$ \\
\hline $\begin{array}{l}\text { Khedr et al. } \\
\text { (2014) [16] }\end{array}$ & $\begin{array}{l}\text { NE: } 11 \\
\text { NC: } 11\end{array}$ & Parallel & $\begin{array}{l}68.5 \pm 7.2 \\
67.3 \pm 5.9\end{array}$ & $\begin{array}{l}3 / 9 \\
6 / 5\end{array}$ & $\begin{array}{c}8.9 \pm 5.1 \\
\text { NR }\end{array}$ & $3.0 \pm 2.6$ & $\begin{array}{l}\text { Mild to } \\
\text { moderate } \\
(\geq 12)\end{array}$ & MMSE & $\begin{array}{l}\text { Anodal; } \\
0.08 \mathrm{~mA} / \mathrm{cm}^{2} \\
25 \mathrm{~min} / \mathrm{d}, 10 \mathrm{~d} ; \\
\text { left DLPFC }\end{array}$ \\
\hline $\begin{array}{l}\text { Khedr et al. } \\
\text { (2019) [17] }\end{array}$ & $\begin{array}{l}\text { NE: } 23 \\
\text { NC: } 23\end{array}$ & RCT & $\begin{array}{l}64.22 \pm 3.64 \\
65.23 \pm 4.52\end{array}$ & $\begin{array}{l}13 / 10 \\
13 / 8\end{array}$ & $\begin{array}{l}4.04 \pm 2.83 \\
3.52 \pm 1.96\end{array}$ & $\begin{array}{l}14.08 \pm 5.79 \\
14.09 \pm 4.68\end{array}$ & $\begin{array}{l}14.17 \pm 3.67 \\
13.90 \pm 3.46\end{array}$ & $\begin{array}{l}\text { MMSE } \\
\text { Clock } \\
\text { drawing test } \\
\text { Cornell } \\
\text { depression } \\
\text { scale }\end{array}$ & $\begin{array}{l}\text { Anodal and cathodal: } \\
2 \mathrm{~mA}, 20 \mathrm{~min} / \mathrm{day}, \\
5 \mathrm{session} / \mathrm{wk} \text { for } \\
2 \mathrm{wk} \text {, right /left } \\
\text { temporal lobe }\end{array}$ \\
\hline
\end{tabular}

Values are presented as mean \pm standard deviation.

$\mathrm{AD}$, Alzheimer disease; $\mathrm{tDCS}$, transcranial direct current stimulation; $\mathrm{B} / \mathrm{L}$, bilateral; $\mathrm{C} / \mathrm{L}$, contralateral; DLPFC, dorsal lateral prefrontal cortex; NC, number of subjects in control group; NE, number of subjects in experimental group; NR, not reported; CVLT-II, California verbal learning test; MODA, Milan Overall Dementia Assessment; FT, Frontotemporal; FNAT, face-name association task; M/F, male/female; MMSE, Mini-Mental State Examination; VRT, visual recognition task; ADAS Cog, Alzheimer's dementia assessment scale-cognitive subscale; CDR, clinical dementia rating scale; FAB, Frontal Assessment Battery; WRT, word recognition task. 


\section{Data Management}

For the purpose of the meta-analysis, the data from the studies were input in the Review Manager (RevMan 5.3) and emerging trends were observed. The effect size was calculated for tDCS in each arm of the studies using the standardized mean difference. For studies where data could not be obtained from tables, we used online software (http://www.graphreader.com/) for obtaining data from the graphs. Appropriate summary statistics were input on RevMan (mean, standard deviation and sample size for continuous variables; and number of incidents and participants for dichotomous variables). Assessment of heterogeneity of studies was done using the $r^{2}$ test. If studies met statistical homogeneity $\left(r^{2}<50 \%\right)$, we used fixed model of meta-analysis or else random effects model was used.

\section{Risk of bias assessment}

A risk of bias assessment was carried out using guidelines of Cochrane Collaboration Network with the help of RevMan 5.3. The assessment was based on the following criteria: (1) Random sequence generation (selection bias); (2) Allocation concealment (selection bias); (3) Blinding of subjects and researcher (implementation bias); (4) Blindness of measurement of outcomes (measurement bias); (5) Integrity of the results (attribution bias); (6) Selective reporting of outcome (reporting bias); (7) Other bias. Following evaluation on these above stated criteria appropriate summary chart was made.

\section{Quality estimate of included studies}

All the included studies underwent a quality estimate analyses using PEDro Scale [8]. The PEDro scale is based on the Delphi list developed in the Department of Epidemiology in the University of Maastricht. The scale is to assess the quality of randomized clinical trials in terms of sufficient statistical information that makes their results interpretable. The scale consists of 11 criteria on which the study is assessed. For each criterion, 1 point is awarded only if the criterion is clearly satisfied. A score of $0-4$ is considered poor, 4-5 fair, 6-8 good and 9-10 excellent.

\section{Assessment of outcome}

All studies included subjects that had a quantitative assessment of the outcome. All the included studies initially had cognitive assessment based on a scale like mini mental status examination (MMSE), Apathy scale etc. or a test like trail making test, word sorting test etc. After intervention in the form of tDCS another assessment of cognitive functions was done. To assess improvement of overall cognitive function we used pre and post intervention scores of MMSE to assess the change. Adverse events reported by the studies and dropout rates between studies was also compared.

\section{Statistical Analyses}

Meta-analysis was conducted on final MMSE scores seen after intervention using a continuous model in RevMan. We used mean, standard deviation and total sample size to derive forest plot charts in the continuous model. We also did separate assessment comparing the effect of various types of tDCS. A funnel plot was used for observing publication bias. Forest plot charts were also made after comparing dropouts and adverse effects across studies.

\section{RESULTS}

\section{Literature Search}

Our literature search was conducted at three data bases viz. Scopus, Pubmed and DOAJ. A total of 1,021 articles were identified out of which finally included 11 studies in our quantitative analysis (Table 1) [9-18]. All the studies included had made two groups viz. sham and active group. 9 out of 11 studies had a parallel design and 2 had cross over design. All the studies included subjects with Alzheimer's disease diagnosed according to DSM 5 and National Institute of Neurological and Communicative Disorders and Stroke-Alzheimer's Disease and Related Disorders Association (NINCDS-ADRDA) criteria. The characteristics of the studies included in this analysis has been depicted in Table 1 given below (Fig. 1).

\section{Quality Estimate Assessment}

Quality estimate was carried out for all included studies and PEDro Scale [8] was used for the same. All the studies included in the meta-analysis were rated "high" quality. However, 4 studies did not mention the details of randomization and 1 study did not mention about the details of blinding procedure followed (Table 2). 


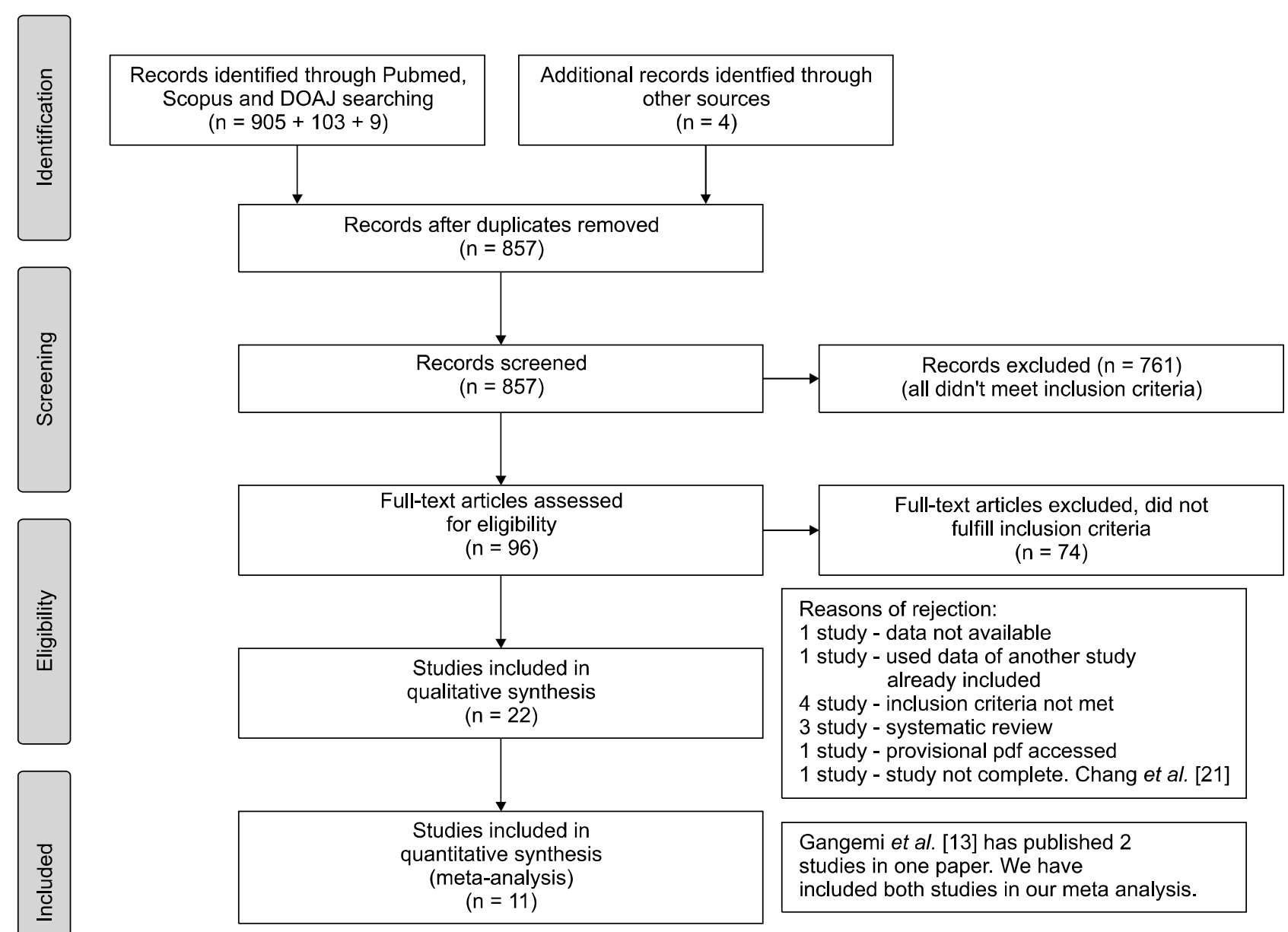

Fig. 1. Table showing the flow of studies in the course of this review.

Table 2. Table showing quality estimate of studies using PEDro scale

\begin{tabular}{|c|c|c|c|c|c|c|c|c|c|c|c|c|}
\hline \multirow{2}{*}{ Studies } & \multicolumn{12}{|c|}{ Criteria of PEDro } \\
\hline & 1 & 2 & 3 & 4 & 5 & 6 & 7 & 8 & 9 & 10 & 11 & Quality \\
\hline Boggio et al. (2012) [10] & Yes & No & No & Yes & Yes & Yes & Yes & Yes & Yes & Yes & Yes & High \\
\hline Bystad et al. (2016) [9] & Yes & Yes & Yes & Yes & Yes & Yes & Yes & Yes & Yes & Yes & Yes & High \\
\hline Cotelli et al. (2014) [11] & Yes & No & No & Yes & Yes & Yes & Yes & Yes & Yes & Yes & Yes & High \\
\hline \multicolumn{13}{|l|}{ Gangemi et al. (2021) [13] } \\
\hline Study 1 & Yes & Yes & Yes & Yes & Yes & Yes & Yes & Yes & Yes & Yes & Yes & High \\
\hline Study 2 & Yes & Yes & Yes & Yes & Yes & Yes & Yes & Yes & Yes & Yes & Yes & High \\
\hline Im et al. (2019) [14] & Yes & No & Yes & Yes & No & No & No & Yes & Yes & Yes & Yes & High \\
\hline Inagawa et al. (2019) [15] & Yes & Yes & Yes & Yes & Yes & Yes & Yes & Yes & Yes & Yes & Yes & High \\
\hline Ferrucci et al. (2008) [12] & Yes & No & Yes & Yes & Yes & Yes & Yes & Yes & Yes & Yes & Yes & High \\
\hline Khedr et al. (2014) [16] & Yes & Yes & Yes & Yes & Yes & Yes & Yes & Yes & Yes & Yes & Yes & High \\
\hline Khedr et al. (2019) [17] & Yes & Yes & Yes & Yes & Yes & Yes & Yes & Yes & Yes & Yes & Yes & High \\
\hline Lu et al. (2019) [18] & Yes & Yes & Yes & Yes & Yes & Yes & Yes & Yes & Yes & Yes & Yes & High \\
\hline
\end{tabular}

\section{Risk of Bias Assessment}

Risk of bias assessment was carried out using RevMan 5.3 using guidelines of Cochrane Collaboration Network.
For almost 7 studies there was low risk of selection bias. Also 1 study had unclear risk of detection bias and performance bias as the details were not mentioned. Overall 
there was low risk of bias in all studies in maximum criteria (Fig. 2A).

A funnel pot was made incorporating the included studies to see for publication bias. The presence of any asymmetrical trend was noted which could be due to publication bias (Fig. 2B).

\section{Meta Analysis of Treatment Effect}

All the subjects in active and sham group were subjected to active and sham stimulation. All the patients were evaluated for cognitive skills using pre and posts stimulation MMSE. All the analysis of treatment effect was done using the final post stimulation MMSE scores in both groups. Forest plots were made separately showing effect of anodal tDCS vs. sham tDCS (Fig. 3A), cathodal tDCS vs. sham tDCS (Fig. 3B), dual tDCS stimulation vs. sham tDCS (Fig. 3C) and overall effect of tDCS vs. sham tDCS (Fig. 3D).

\section{Effect of Anodal tDCS}

Seven out of 11 studies used Anodal tDCS in the active group. Stimulation was given in frontal lobe, temporal lobe, parieto temporal lobe and dorsal lateral prefrontal cortex across these 7 studies. Period of stimulation across these 7 studies ranged from 10 days to 10 days each month for 8 months. A current ranging from $0.06 \mathrm{~mA}$ to $2.5 \mathrm{~mA}$ per $\mathrm{cm}^{2}$ was applied. Heterogeneity was present across studies $\left(\chi^{2}=27.3, p=0.0001, r^{2}=78 \%\right)$ and a random effects model was used for analysis. A total of 89 patients were given AtDCS in active group. Statistically significant improvement was found in the MMSE scores of anodal tDCS group against sham group.

\section{Effect of Cathodal tDCS}

Two out of 11 studies used cathodal tDCS in the active group. Stimulation was given in temporal lobe across these 2 studies. Period of stimulation across these 2 studies ranged from 2 weeks to 3 months. A current ranging from $0.06 \mathrm{~mA}$ to $2 \mathrm{~mA}$ per $\mathrm{cm}^{2}$ was applied. Heterogeneity was present across studies $\left(\chi^{2}=125.49, p \leq 0.0001, l^{2}=\right.$ $99 \%$ ) and a random effects model was used for analysis. A total of 22 patients were given cathodal tDCS in active
A

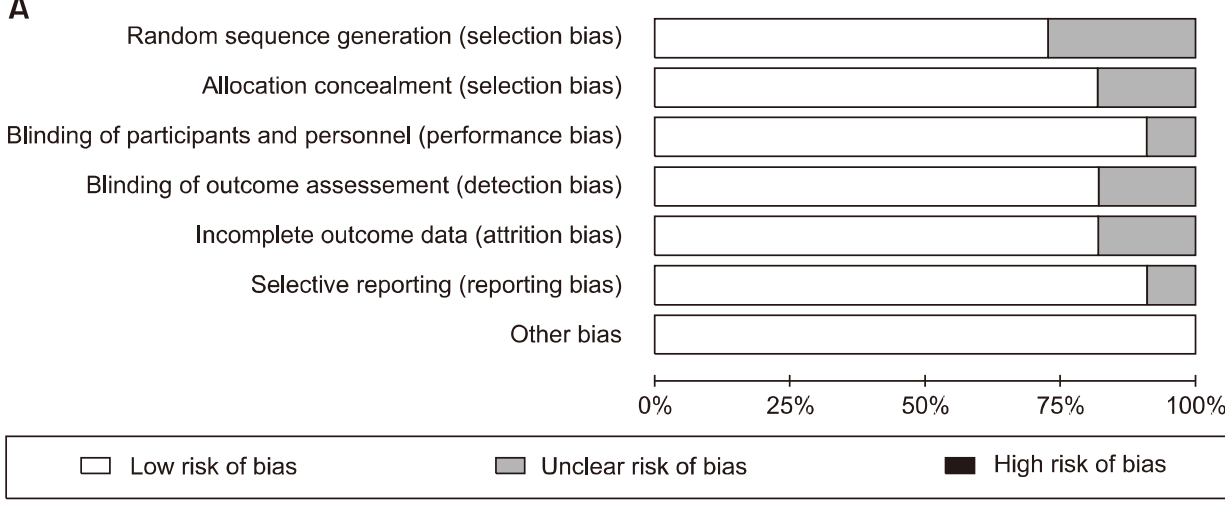

B

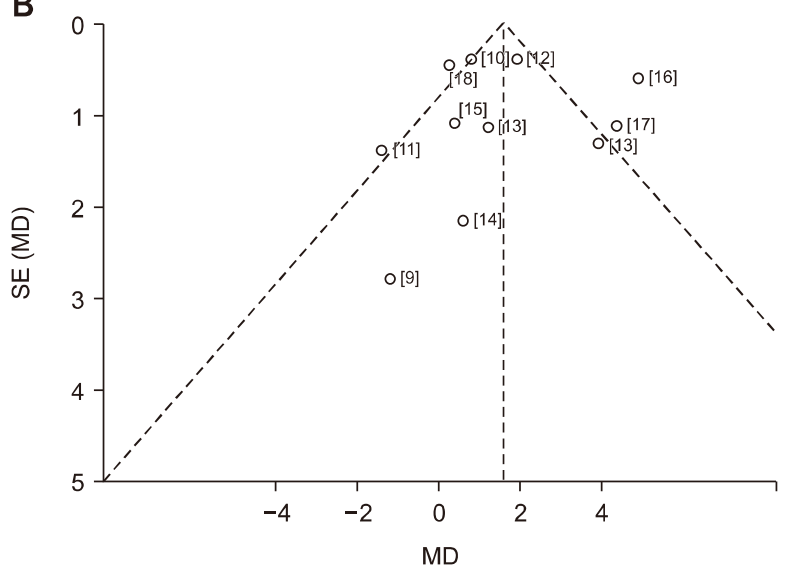

Fig. 2. (A) Table showing bias assessment of studies. (B) Funnel chart showing asymmetrical distribution of the studies in Funnel plot. $\mathrm{SE}$, standard error; MD, log odds ratio. 


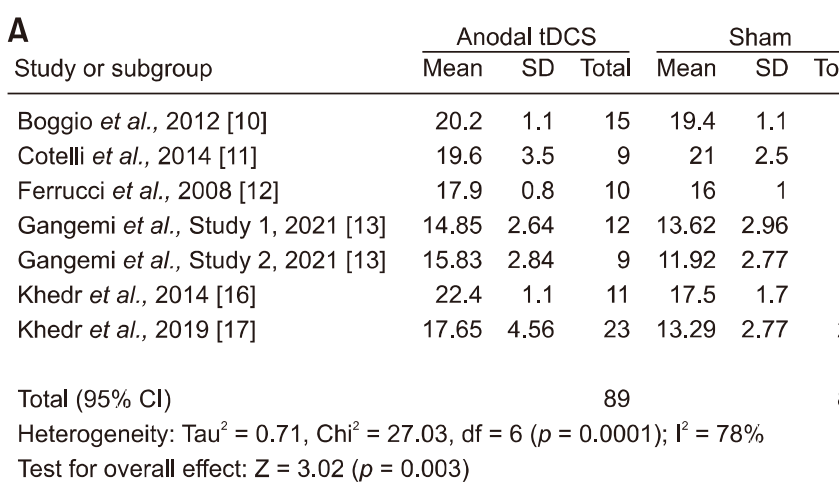

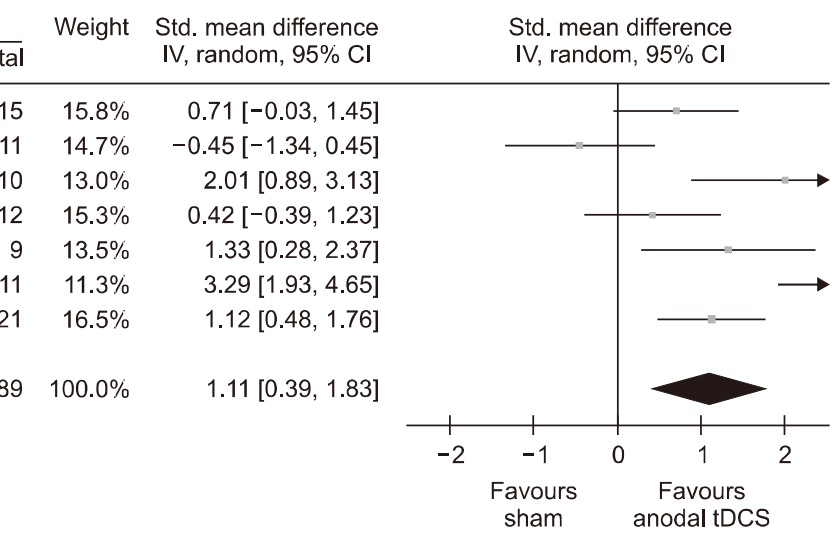

B

\begin{tabular}{|c|c|c|c|c|c|c|c|c|}
\hline \multirow{2}{*}{ Study or subgroup } & \multicolumn{3}{|c|}{ Cathodal tDCS } & \multicolumn{3}{|c|}{ Sham } & \multirow[t]{2}{*}{ Weight } & \multirow{2}{*}{$\begin{array}{l}\text { Std. mean difference } \\
\text { IV, random, } 95 \% \mathrm{Cl}\end{array}$} \\
\hline & Mean & SD & Total & $\overline{\text { Mean }}$ & SD & Total & & \\
\hline Ferrucci et al., 2008 [12] & 13.2 & 0.9 & 10 & 16 & 1 & 10 & $71.3 \%$ & $-2.80[-3.63,-1.97]$ \\
\hline Khedr et al., 2014 [16] & 23.6 & 1.5 & 12 & 17.5 & 1.7 & 11 & $28.7 \%$ & $6.10[4.78,7.42]$ \\
\hline Total $(95 \% \mathrm{Cl})$ & & & 22 & & & 21 & $100.0 \%$ & $-0.25[-0.95,0.46]$ \\
\hline
\end{tabular}

Test for overall effect: $Z=0.69(p=0.49)$

\section{C}

Study or subgroup

Bystad et al., 2016 [9]

Im et al., 2019 [14]

Inagawa et al., 2019 [15]

Lu et al., 2019 [18]

\begin{tabular}{rrr}
\multicolumn{3}{c}{ Dual tDCS } \\
\hline Mean & SD & T \\
21 & 6.6 \\
21.2 & 4.4 \\
25.2 & 2.3 \\
26.02 & 2.75
\end{tabular}

Total $(95 \% \mathrm{Cl})$

99

Heterogeneity: $\mathrm{Chi}^{2}=0.43, \mathrm{df}=3(p=0.93) ; I^{2}=0 \%$

Test for overall effect: $Z=0.53(p=0.60)$

\section{D}

Study or subgroup

Boggio et al., 2012 [10]

Bystad et al., 2016 [9]

Cotelli et al., 2014 [11]

Ferrucci et al., 2008 [12]

Gangemi et al., Study 1, 2021 [13]

Gangemi et al., Study 2, 2021 [13]

Im et al., 2019 [14]

Inagawa et al., 2019 [15]

Khedr et al., 2014 [16]

Khedr et al., 2019 [17]

Lu et al., 2019 [18]

$\frac{\text { tDCS }}{\text { Mean SD Total }} \frac{2 \text { Sham }}{\text { Mean SD Total }}$

$\begin{array}{rr}20.2 & 1.1 \\ 21 & 6.6\end{array}$

$19.6 \quad 3.5$

$\begin{array}{ll}17.9 & 0.8\end{array}$

$14.85 \quad 2.64$

$15.83 \quad 2.84$

$\begin{array}{ll}21.2 & 4.4\end{array}$

$25.2 \quad 2.3$

$\begin{array}{ll}22.4 & 1.1\end{array}$

$17.65 \quad 4.56$

$26.02 \quad 2.75$

$\begin{array}{lll}15 & 19.4 & 1.1\end{array}$

$\begin{array}{lll}12 & 22.2 & 7.4\end{array}$

$9 \quad 21 \quad 25$

$\begin{array}{rrr}10 & 16 & 1\end{array}$

$12 \quad 13.62 \quad 296$

$\begin{array}{lll}9 & 11.92 & 2.77\end{array}$

$\begin{array}{lll}11 & 20.6 & 4.5\end{array}$

$\begin{array}{lll}7 & 24.8 & 2.4\end{array}$

$\begin{array}{lll}11 & 17.5 & 1.7\end{array}$

$\begin{array}{llll}23 & 13.29 & 2.77\end{array}$

$\begin{array}{lll}69 & 25.74 & 2.67\end{array}$

188

Total $(95 \% \mathrm{Cl})$

Heterogeneity: $\mathrm{Tau}^{2}=2.55, \mathrm{Chi}^{2}=57.85, \mathrm{df}=10(p<0.00001) ; \mathrm{I}^{2}=83 \%$

Test for overall effect: $Z=2.87(p=0.004)$

Weight Std. mean difference IV, random, $95 \% \mathrm{CI}$

$0.80[0.01,1.59]$

$-1.20[-6.69,4.29]$

$-1.40[-4.12,1.32]$

$1.90[1.11,2.69]$

$1.23[-1.01,3.47]$

$3.91[1.32,6.50]$

$0.60[-3.63,4.83]$

$0.40[-1.75,2.55]$

$4.90[3.70,6.10]$

$4.36[2.15,6.57]$

$0.28[-0.64,1.20]$

$1.68[0.53,2.83]$
Std. mean difference IV, random, $95 \% \mathrm{Cl}$

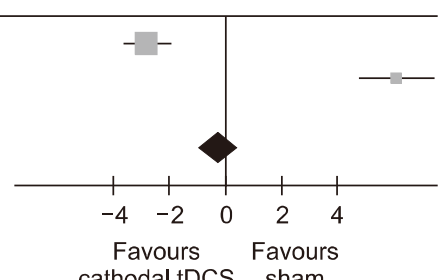


group. No statistically significant improvement was found in the MMSE scores of cathodal tDCS group against Sham group.

\section{Effect of Dual Stimulation tDCS}

Four out of 11 studies used dual stimulation tDCS in the active group. Dual stimulation has been defined as stimulation to two parallel cortices, purposefully upregulating one region of the brain, while downregulating another [19]. Stimulation was given in temporal lobe across these 4 studies. Period of stimulation across these 4 studies ranged from 2 weeks to 3 months. A current ranging from $0.06 \mathrm{~mA}$ to $2 \mathrm{~mA}$ per $\mathrm{cm}^{2}$ was applied. Homogeneity was present across studies $\left(\chi^{2}=0.43, p=0.93, l^{2}=0 \%\right)$ and a fixed effects model was used for analysis. A total of 99 patients were given dual stimulation tDCS in active group. No statistically significant improvement was found in the MMSE scores of dual stimulation tDCS group against sham group.

\section{Overall Effect of tDCS}

A total of 11 studies were analysed in this part of our analyses irrespective of the type of tDCS administered. Period of stimulation across these 11 studies ranged from 2 weeks to 8 months. A current ranging from $0.06 \mathrm{~mA}$ to 2 $\mathrm{mA}$ per $\mathrm{cm}^{2}$ was applied. Heterogeneity was present

A

\begin{tabular}{|c|c|c|c|c|c|}
\hline \multirow{2}{*}{$\begin{array}{l}\text { A } \\
\text { Study or subgroup }\end{array}$} & \multicolumn{2}{|c|}{ tDCS } & \multicolumn{2}{|c|}{ Sham } & \multirow[t]{2}{*}{ Wei } \\
\hline & Events & Total & Events & Total & \\
\hline Boggio et al., 2012 [10] & 0 & 15 & 0 & 15 & \\
\hline Bystad et al., 2016 [9] & 0 & 12 & 0 & 13 & \\
\hline Cotelli et al., 2014 [11] & 3 & 12 & 1 & 12 & \\
\hline Ferrucci et al., 2008 [12] & 0 & 20 & 0 & 10 & \\
\hline Gangemi et al., 2021 [13] & 0 & 13 & 0 & 13 & \\
\hline Im et al., 2019 [14] & 1 & 12 & 1 & 8 & \\
\hline Inagawa et al., 2019 [15] & 0 & 7 & 1 & 13 & \\
\hline Khedr et al., 2014 [16] & 0 & 23 & 0 & 11 & \\
\hline Khedr et al., 2019 [17] & 0 & 23 & 2 & 23 & \\
\hline Lu et al., 2019 [18] & 8 & 69 & 10 & 64 & \\
\hline Total $(95 \% \mathrm{Cl})$ & & 206 & & 182 & \\
\hline Total events & 12 & & 15 & & \\
\hline \multirow{2}{*}{\multicolumn{6}{|c|}{$\begin{array}{l}\text { Heterogeneity: } \mathrm{Chi}^{2}=2.50, \mathrm{df}=4(p=0.65) ; I^{2}=0 \% \\
\text { Test for overall effect: } Z=0.70(p=0.48)\end{array}$}} \\
\hline & & & & & \\
\hline
\end{tabular}

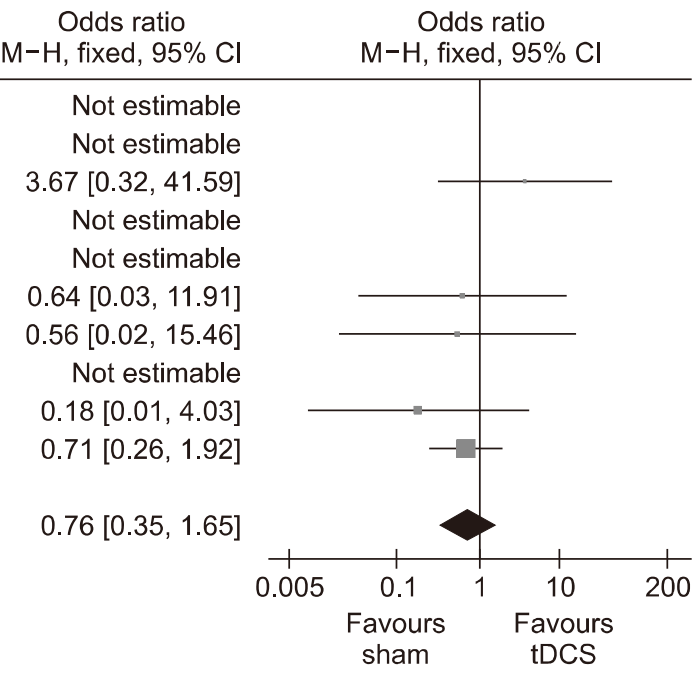

\begin{tabular}{|c|c|c|c|c|c|c|c|c|c|c|}
\hline \multirow{3}{*}{$\begin{array}{l}\text { B } \\
\text { Study or subgroup } \\
\text { Boggio et al., } 2012 \text { [10] }\end{array}$} & \multicolumn{2}{|c|}{ tDCS } & \multicolumn{2}{|c|}{ Sham } & \multirow[t]{2}{*}{ Weight } & \multirow{2}{*}{$\begin{array}{c}\text { Odds ratio } \\
\mathrm{M}-\mathrm{H} \text {, fixed, } 95 \% \mathrm{Cl}\end{array}$} & \multirow{2}{*}{\multicolumn{3}{|c|}{$\begin{array}{c}\text { Odds ratio } \\
\mathrm{M}-\mathrm{H} \text {, fixed, } 95 \% \mathrm{Cl}\end{array}$}} & \\
\hline & \multirow{2}{*}{$\begin{array}{c}\text { Events } \\
0\end{array}$} & \multirow{2}{*}{$\begin{array}{r}\text { Total } \\
15\end{array}$} & \multirow{2}{*}{$\begin{array}{c}\text { Events } \\
0\end{array}$} & \multirow{2}{*}{$\begin{array}{r}\text { Total } \\
15\end{array}$} & & & & & & \\
\hline & & & & & & Not estimable & & & & \\
\hline Bystad et al., 2016 [9] & 0 & 12 & 0 & 13 & & Not estimable & & & & \\
\hline Cotelli et al., 2014 [11] & 0 & 12 & 0 & 12 & & Not estimable & & & & \\
\hline Ferrucci et al., 2008 [12] & 0 & 20 & 0 & 10 & & Not estimable & & & & \\
\hline Gangemi et al., 2021 [13] & 0 & 13 & 0 & 13 & & Not estimable & & & & \\
\hline Im et al., 2019 [14] & 0 & 12 & 0 & 8 & & Not estimable & & & & \\
\hline Inagawa et al., 2019 [15] & 0 & 7 & 0 & 13 & & Not estimable & & & & \\
\hline Khedr et al., 2014 [16] & 2 & 23 & 0 & 11 & $38.7 \%$ & $2.67[0.12,60.54]$ & & & - & \\
\hline Khedr et al., 2019 [17] & 2 & 23 & 0 & 23 & $29.0 \%$ & $5.47[0.25,120.37]$ & & & & \\
\hline Lu et al., 2019 [18] & 2 & 69 & 0 & 64 & $32.4 \%$ & $4.78[0.23,101.44]$ & & & & \\
\hline Total $(95 \% \mathrm{Cl})$ & & 127 & & 111 & $100.0 \%$ & $4.16[0.70,24.69]$ & & & & \\
\hline Total events & 6 & & 0 & & & & & & & 200 \\
\hline $\begin{array}{l}\text { Heterogeneity: } \mathrm{Chi}^{2}=0.11 \text {, } \\
\text { Test for overall effect: } Z=1\end{array}$ & $\begin{array}{l}2(p=0 \\
(p=0.12\end{array}$ & 4); & & & & & 0.005 & $\begin{array}{l}\text { Favours } \\
\text { sham }\end{array}$ & $\begin{array}{c}\text { Favours } \\
\text { tDCS }\end{array}$ & 200 \\
\hline
\end{tabular}

Fig. 4. Forest plot of studies comparing (A) drop outs in group receiving tDCS and sham tDCS. (B) Adverse effects reported in group receiving tDCS and sham tDCS.

tDCS, transcranial direct current stimulation; $\mathrm{Cl}$, confidence interval. 
across studies $\left(\chi^{2}=57.85, \mathrm{p} \leq 0.00001, \rho^{2}=83 \%\right)$ and a random effects model was used for analysis. A total of 188 patients were given tDCS in active group. Statistically significant improvement was found in the MMSE scores of tDCS group against sham group.

\section{Meta Analysis of Drop Outs}

Five studies out of 11 included studies have reported drop outs and a meta analysis for the same was performed. Homogeneity was present across studies $\left(\chi^{2}=\right.$ 2.5, $p=0.65, l^{2}=0$ ) and a fixed effects model was used for analysis. A total of 15 patients dropped out in the sham group and 12 patients dropped out from tDCS group. No statistically significant difference was found in drop outs of sham and tDCS group (Fig. 4A).

\section{Meta Analysis of Adverse Effects}

Three out of 11 studies have reported adverse effects. Mild side effects in the form of tingling, headache, heaviness in head, itching were reported by patients. A total of 6 adverse effects were reported in the tDCS group and no adverse effects were reported in sham group. Homogeneity was present across studies $\left(\chi^{2}=1.1, p=\right.$ $0.94, r^{2}=0$ ) and a fixed effects model was used for analysis. No statistically significant difference was found in adverse effects of sham and tDCS groups (Fig. 4B).

\section{DISCUSSION}

tDCS is an upcoming modality of treatment amongst brain stimulation techniques. The ease and convenience of administering the procedure and the low cost incurred, make it a very feasible option of treatment. Owing to these factors, the effects of tDCS in improving cognitive decline in patients with $\mathrm{AD}$ were analysed. We analysed a total of 11 studies published between January 2000 \& June 2020. All the studies had undergone randomization and blinding although one study did not give the details of blinding procedure involved.

tDCS promotes and inhibits the spontaneous activity of cerebral cortex. tDCS stimulates the brain with weak currents of around $2 \mathrm{~mA}$ and regulates the resting membrane potential. This induces changes at the levels of spontaneous discharges and results in activation of NMDA receptor. The effect of tDCS is dependent on the montage that is used. Anodal tDCS is known to result in cortical ex- citability by causing depolarisation, whereas cathodal tDCS results in decrease of cortical excitability by causing hyperpolarisation [20]. In addition to that, tDCS also results regional cerebral blood flow changes and impedes the aberrant neural synchronization that is seen in AD.

Previous reviews conducted on this theme have identified that the results of tDCS in cognition of patients with $\mathrm{AD}$ has been conflicting [21]. The queries regarding the most effective montage and the optimal session frequency and duration has been raised in most reviews [6,7]. In our review, all studies had their follow up ranging from 2 weeks to 8 months and the sample size ranged from 20 to 210. The studies were heterogenous in the frequency and total number of sessions administered (Table 1). But overall, the results of our meta-analysis showed that tDCS was effective in improving cognition of patients with AD. Also, on evaluating for the type of stimulation that was more effective, Anodal stimulation was most effective in cognitive improvement of subjects with Alzheimer's disease. However, long term follow up studies will be required to see full effects of tDCS.

tDCS is known to have certain mild adverse effects like headache, tingling, numbness after the procedure that lasts for few hours. However our analyses should that tDCS was well tolerated in patients with AD as our analyses did not report statistically significant drop outs and adverse effects in sham or tDCS groups.

The strength of our analyses was that all the studies that have been included in the analyses have a low risk of bias and had a high score on quality estimate. Secondly, we have analysed the type of tDCS stimulation that is most effective in improving cognition of person with $A D$. According to our knowledge this is the first study to have analysed the type of stimulation in tDCS.

Our meta-analysis had a number of limitations. Firstly, we could only analyze literature published in English language and could not include studies published in other languages like French, German etc. Secondly, although all included studies had undergone randomization and were conducted with blinding, there was high heterogeneity amongst our studies. The high variability in sample size, duration of illness, duration of tDCS, type of stimulation, current intensity could have contributed to the same. Finally, only MMSE scores were chosen for analysis. The other aspects of cognition like visuo-spatial skills, language etc were not analyzed in our study. 
We intend to extend our analysis in a few respects in near future. We would like to assess the effect of tDCS in behavioural and psychological symptoms of Dementia in subjects with AD. Also, we would like to evaluate effects of tDCS on other aspects of cognition like visual and spatial skills, language etc. It is important to see the effects of tDCS on these aspects of cognition and to assess if they also improve with tDCS or the improvement that we see in MMSE is at the expense of these functions? Also, the applicability of tDCS in improvement of other types of dementias like Lewy body dementia, Frontotemporal Dementia, Dementia secondary to traumatic brain injury, HIV, Parkinson's disease needs consideration.

To conclude, tDCS is found to be effective in improving cognition of patients with Alzheimer's disease. Anodal tDCS is more effective than dual stimulation and cathodal tDCS. tDCS is well tolerated in patients with Alzheimer's disease.

\section{acknowledgments}

Dr. Prithwish Ghosh, research fellow, Department of Gastroenterology, Mayo Clinic, Rochester, USA for his help in data analysis.

\section{Conflicts of Interest}

No potential conflict of interest relevant to this article was reported.

\section{Author Contributions}

Conceptualization: Vrinda Saxena, Arghya Pal. Data acquisition: Vrinda Saxena, Arghya Pal. Formal analysis: Vrinda Saxena, Arghya Pal. Funding: Nil. Supervision: Arghya Pal. Writing-original draft: Vrinda Saxena, Arghya Pal. Writing-review \& editing: Vrinda Saxena, Arghya Pal.

\section{ORCID}

Vrinda Saxena

https://orcid.org/0000-0002-2497-6564

Arghya Pal

https://orcid.org/0000-0002-5887-1971

\section{REFERENCES}

1. American Psychiatric Association. Diagnostic and statistical manual of mental disorders (DSM-5) [Internet]. Virginia: American Psychiatric Association; 2016 Jan 31 [cited at 2020 Apr 20]. Available from: http://www.dsm5.org/Pages/Default. aspx.
2. Takizawa C, Thompson PL, van Walsem A, Faure C, Maier WC. Epidemiological and economic burden of Alzheimer's disease: a systematic literature review of data across Europe and the United States of America. I Alzheimers Dis 2015; 43:1271-1284

3. Budson AE, Solomon PR. New criteria for A/zheimer disease and mild cognitive impairment: implications for the practicing clinician. Neurologist 2012;18:356-363.

4. Mendiola-Precoma J, Berumen LC, Padilla K, Garcia-Alcocer G. Therapies for prevention and treatment of Alzheimer's disease. Biomed Res Int 2016;2016:2589276.

5. Cruz Gonzalez P, Fong KNK, Chung RCK, Ting KH, Law LLF, Brown T. Can transcranial direct-current stimulation alone or combined with cognitive training be used as a clinical intervention to improve cognitive functioning in persons with mild cognitive impairment and dementia? A systematic review and meta-analysis. Front Hum Neurosci 2018;12:416.

6. Cai M, Guo Z, Xing G, Peng H, Zhou L, Chen H, et al. Transcranial direct current stimulation improves cognitive function in mild to moderate Alzheimer disease: a metaanalysis. Alzheimer Dis Assoc Disord 2019;33:170-178.

7. Inagawa T, Narita Z, Sugawara N, Maruo K, Stickley A, Yokoi $\mathrm{Y}$, et al. A meta-analysis of the effect of multisession transcranial direct current stimulation on cognition in dementia and mild cognitive impairment. Clin EEG Neurosci 2019; 50:273-282.

8. Cashin AG, McAuley JH. Clinimetrics: Physiotherapy Evidence Database (PEDro) scale. J Physiother 2020;66:59.

9. Bystad M, Grønli O, Rasmussen ID, Gundersen N, Nordvang $\mathrm{L}$, Wang-Iversen $\mathrm{H}$, et al. Transcranial direct current stimulation as a memory enhancer in patients with Alzheimer's disease: a randomized, placebo-controlled trial. Alzheimers Res Ther 2016:8:13.

10. Boggio PS, Ferrucci R, Mameli F, Martins D, Martins O, Vergari M, et al. Prolonged visual memory enhancement after direct current stimulation in Alzheimer's disease. Brain Stimul 2012:5:223-230

11. Cotelli M, Manenti R, Brambilla M, Petesi M, Rosini S, Ferrari $\mathrm{C}$, et al. Anodal tDCS during face-name associations memory training in Alzheimer's patients. Front Aging Neurosci 2014; $6: 38$.

12. Ferrucci R, Mameli F, Guidi I, Mrakic-Sposta S, Vergari M, Marceglia S, et al. Transcranial direct current stimulation improves recognition memory in Alzheimer disease. Neurology 2008;71:493-498.

13. Gangemi A, Colombo B, Fabio RA. Effects of short-and long-term neurostimulation (tDCS) on Alzheimer's disease patients: two randomized studies. Aging Clin Exp Res 2021; 33:383-390.

14. Im JJ, Jeong $\mathrm{H}$, Bikson M, Woods AJ, Unal G, Oh JK, et al. Effects of 6-month at-home transcranial direct current stimulation on cognition and cerebral glucose metabolism in Alzheimer's disease. Brain Stimul 2019;12:1222-1228. 
15. Inagawa T, Yokoi Y, Narita Z, Maruo K, Okazaki M, Nakagome K. Safety and feasibility of transcranial direct current stimulation for cognitive rehabilitation in patients with mild or major neurocognitive disorders: a randomized shamcontrolled pilot study. Front Hum Neurosci 2019;13:273.

16. Khedr EM, Gamal NF, El-Fetoh NA, Khalifa H, Ahmed EM, Ali $\mathrm{AM}$, et al. A double-blind randomized clinical trial on the efficacy of cortical direct current stimulation for the treatment of Alzheimer's disease. Front Aging Neurosci 2014;6:275.

17. Khedr EM, Salama RH, Abdel Hameed M, Abo Elfetoh N, Seif $\mathrm{P}$. Therapeutic role of transcranial direct current stimulation in Alzheimer disease patients: double-blind, placebo-controlled clinical trial. Neurorehabil Neural Repair 2019;33:384-394.
18. Lu H, Chan SSM, Chan WC, Lin C, Cheng CPW, Linda Chiu Wa L. Randomized controlled trial of TDCS on cognition in 201 seniors with mild neurocognitive disorder. Ann Clin Trans/ Neurol 2019;6:1938-1948.

19. Thair H, Holloway AL, Newport R, Smith AD. Transcranial direct current stimulation (tDCS): a beginner's guide for design and implementation. Front Neurosci 2017;11:641.

20. Murugaraja $\vee$, Shivakumar $\vee$, Sinha $P$, Venkatasubramanian G, Sivakumar P. Transcranial direct current stimulation for mild cognitive impairment. / Geriatr Ment Health 2017;4: 106-114.

21. Chang CH, Lane HY, Lin CH. Brain stimulation in Alzheimer's disease. Front Psychiatry 2018;9:201. 